\title{
Unravelling collaboration mechanisms for green logistics: the perspectives of shippers and logistics service providers
}

\author{
Amer Jazairy ${ }^{(0)}$ and Robin von Haartman ${ }^{(0)}$ \\ Department of Industrial Management, \\ Industrial Design and Mechanical Engineering, University of Gävle, \\ Gävle, Sweden, and \\ Maria Björklund ${ }^{\circledR}$ \\ Department of Management and Engineering, Linköping University, \\ Linköping, Sweden
}

Collaboration mechanisms for green logistics

Received 5 September 2019 Revised 9 April 2020 27 October 2020 27 January 2021 11 February 2021 Accepted 15 February 2021

\begin{abstract}
Purpose - The green logistics literature remains undecided on how collaboration between shippers (i.e. logistics buyers) and logistics service providers (LSPs) may facilitate green logistics practices (GLPs). This paper identifies two types of collaboration mechanisms, relation specific and knowledge sharing, to systematically examine their influence on facilitating the different types of GLPs - as seen by shippers versus LSPs.

Design/methodology/approach - Survey responses of 169 shippers and 162 LSPs in Sweden were collected and analysed using exploratory- and confirmatory factor analysis, followed by multiple regression analysis.

Findings - The findings reveal that neither of the actors consistently favour a certain type of collaboration mechanisms for facilitating all types of GLPs. Although it was found that both actors share the same view on the role of collaboration mechanisms for some GLPs, their views took contrasting forms for others.

Research limitations/implications - This study contributes to the green logistics literature by incorporating a trilateral distinction to present collaboration recommendations for GLPs, based on (1) the collaboration mechanism at play, (2) the actor's perspective and (3) the GLP in question.

Practical implications - Insights are offered to managers at shipper/LSP firms to apply the right ("fit for purpose") collaboration mechanisms in their relationships with their logistics partners with respect to the desired GLPs.

Originality/value - This is one of the first large-scale studies to systematically reveal in what way collaboration can facilitate the different types of GLPs.
\end{abstract}

Keywords Environmental sustainability, Green supply chain management, Third-party logistics, 3PL, LSP, Sweden, Survey, Transport, Relational view

Paper type Research paper

(C) Amer Jazairy, Robin von Haartman and Maria Björklund. Published by Emerald Publishing Limited. This article is published under the Creative Commons Attribution (CC BY 4.0) licence. Anyone may reproduce, distribute, translate and create derivative works of this article (for both commercial and noncommercial purposes), subject to full attribution to the original publication and authors. The full terms of this licence may be seen at http://creativecommons.org/licences/by/4.0/legalcode

The authors would like to cordially thank the co-funders, Region Gävleborg and Tillväxtverket for funding CLIP 4.0., the Centre for Logistics and Innovative Production at the University of Gävle, as well as Vinnova, the Swedish innovation agency, grant no. 2019-03180 Innovative interorganizational interaction and business models for climate smart freight transport, for making this research possible.

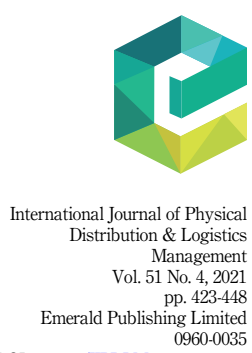

DOI 10.1108/IJPDLM-09-2019-0274 
IJPDLM 51,4

\section{Introduction}

Despite logistics service providers' (LSPs) increased adoption of different green logistics practices (GLPs) over the past decade (Centobelli et al., 2020; Lieb and Lieb, 2010), LSPs' progress is occurring at a rather slow pace (Evangelista et al., 2017), falling short of reaching long-term sustainable development goals (Nilsson et al., 2017). LSPs' implementation of GLPs (e.g. green modal shifts, alternative fuels, green warehousing) is to a large extent dependent on the relationships formed with, and the actions made by, shippers (i.e. logistics buyers) (Huge-Brodin et al., 2020). Consequently, a substantial share of responsibility lies with shippers as well, since they are the ones deciding which LSP to operate and setting the demands for the GLPs to be deployed (Jazairy, 2020; Wolf and Seuring, 2010). Despite the criticality of both actors' responsibilities, knowledge is still limited on how the type of relationships formed between them may support the facilitation of GLPs, and the call for research targeting this area is increasing (Bask et al., 2018; Centobelli et al., 2017; Evangelista et al., 2018).

Several academics emphasize shipper-LSP collaboration as the way forward for facilitating GLPs (see, e.g. Abbasi and Nilsson, 2016; Evangelista et al., 2018; Sallnäs and Huge-Brodin, 2018). Sallnäs and Huge-Brodin (2018), for instance, wrote, "if either LSPs or shippers want to increase environmental practices in their relationships with each other, closer and more frequent collaboration is recommended" (p. 285). Such recommendations are based on the idea that joint commitments and efforts, by both actors, are required to achieve sustainable development goals in the logistics industry. Considering the very diverse natures of GLPs - strategic, tactical or operational (Neto et al., 2008); macro or micro level (Aronsson and Huge-Brodin, 2006); administrative, analytical or transport-related (Lieb and Lieb, 2010) - one may question if collaboration is needed for each one of these. This is inspired by the notion that collaboration can be costly, as it entails commitments to binding agreements and intensification of transactional costs (de Leeuw and Fransoo, 2009; Huo et al., 2017). Cox and Thompson (1997) were early to stress that firms should not view close relationships as the "best way" to form an outsourcing relationship; rather, they should consider the right ("fit for purpose") relationship based on the strategic gains anticipated from it. Besides, the green logistics literature remains vague about prescribing a certain collaboration mechanism for facilitating the GLPs. For instance, it is not clear whether shippers and LSPs need to delve into relation-specific investments over long contracting periods for the GLPs or otherwise intensify knowledge exchange and IT integration towards that end. Building on a mutual point of departure is vital here, as misunderstandings may result in unnecessary costs and efforts that should be avoided in logistics relationships. This knowledge gap makes the current collaboration recommendations for GLPs rather superficial due to their insensitivity to the diverse natures of GLPs as well as the different collaboration mechanisms at play.

Another gap should be stressed. Shippers and LSPs represent entirely different actors, as they operate in different industries and political climates (Selviaridis and Spring, 2007) and apply GLPs for different strategic reasons (Huge-Brodin et al., 2020). LSPs, for instance, possess the competencies for developing GLPs (Colicchia et al., 2013), and apply them to attract environmentally conscious shippers (Sallnäs, 2016). Shippers, on the other hand, engage in GLPs as part of their purchasing strategy (Large et al., 2013), and demand them to compensate for the environmental damage of their own industries (Jazairy and von Haartman, 2020). LSPs are generally seen as more environmentally committed (in providing GLPs) compared to shippers (in purchasing them) (Jazairy and von Haartman, 2021; Martinsen and Björklund, 2012; Wolf and Seuring, 2010). Given the tight profit margins under which LSPs operate (Piecyk and Björklund, 2015), they frequently call for shippers' long-term commitments to secure the return on investment of their green ventures (Goh, 2020; Nilsson et al., 2017), whilst shippers frequently refrain from these commitments to maintain their flexibility in the market (Jazairy, 2020). Nonetheless, the literature is still undecided on the 
actors' diverse buyer-supplier roles when promoting their collaboration for GLPs, which may give an inaccurate impression that they collaborate for the same reasons.

Based on the rationale above, the purpose of this paper is to increase knowledge of the role of collaboration mechanisms in facilitating the different types of GLPs, as seen from the perspectives of shippers against those of LSPs. Two research questions are formulated:

RQ1. Which collaboration mechanisms between shippers and LSPs are required for facilitating the different types of GLPs?

$R Q 2$. To what extent do shippers and LSPs share the view regarding the influence of different collaboration mechanisms on facilitating the different types of GLPs?

Collaboration mechanisms are defined in this paper as means to safeguard close shipper-LSP relationships during their course. For the empirical part of this paper, we utilize the findings of a large-scale survey of shippers and LSPs operating in Sweden - thus fulfilling three targets: (1) establishing satisfactory external validity for associating collaboration mechanisms with the different GLPs, (2) responding to scholarly demands for differentiating between shippers' and LSPs' views of GLPs and (3) countering the underrepresentation of LSPs in the green logistics literature. The findings of this paper contribute to the body of knowledge by systematically revealing, in a GLP-specific manner, whether (and in what way) shipper-LSP collaboration may influence the facilitation of GLPs - and from which actor's viewpoint. This understanding can aid practitioners at shipper/LSP firms to strategically and efficiently channel their collaborative efforts towards specifically desired GLPs during their relationships.

\section{Theoretical framework}

Relationships between shippers and LSPs, like any buyer-supplier relationship in supply chains, take different shapes based on the closeness of their interactions, ranging from basic, arm's-length arrangements to advanced, collaborative partnerships (Bowersox, 1990; Brekalo and Albers, 2016). This paper focuses on the closest form, here termed "collaboration" and defined in line with Cao and Zhang (2011, p. 166) as "two or more autonomous firms work[ing] closely to plan and execute supply chain operations toward common goals and mutual benefits".

\section{Collaboration mechanisms}

The relational view (RV) provides an understanding of why buyers and suppliers in supply chains collaborate. The central principle of RV holds that "a pair or network of firms can develop relationships that result in sustained competitive advantage" (Dyer and Singh, 1998, p. 675). Under this view, competitive advantage yields relational rents (i.e. profit jointly generated in an exchange relationship that cannot be generated by either firm in isolation), based on the notion that the firm's critical resources may span across its organisational boundary (Dyer and Singh, 1998). The choice to collaborate with suppliers is originally linked to the outsourcing decision. Understanding why firms outsource in the first place, rather than internalizing their transactions, is deeply rooted in transaction cost economics (TCE) (Williamson, 1979). TCE's main argument centres on Coase's (1937) three transactional costs: information, bargaining and enforcement. Minimizing these costs shapes the firm's decision to outsource, and these can be evaluated based on their frequency, uncertainty and, most importantly, asset specificity (Williamson, 1981). Asset specificity can be defined as "investments related to a specific transaction and with a limited value when used in alternative applications" (Skjøtt-Larsen, 2000, p. 116); firms form collaborative partnerships as asset specificity increases (Cox and Thompson, 1997). However, firms in supply chains choose to collaborate for reasons beyond pure cost considerations (Sinkovics et al., 2018). This

Collaboration mechanisms for green logistics

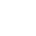


IJPDLM 51,4 is where RV complements TCE. Building on TCE's premises, RV puts forth two key collaboration mechanisms: relation specific and knowledge sharing - described next.

Relation-specific mechanisms - Theses mechanisms safeguard shipper-LSP relationships based on their unique design. As RV contends, investing in relation-specific assets enables the collaborating partners to interlock in their relationship and generate relational rents (Huo et al., 2017) because such assets are stable, irreplaceable and inimitable (Dyer and Singh, 1998). Relation-specific assets encompass tangible (e.g. equipment, plants) and intangible assets (e.g. expertise, knowledge) (Zacharia et al., 2011). Relation-specific assets are often tied up with the degrees of customization of services, where these become particularly suited to the demands of a particular client (i.e. customized, in a relation-specific manner) (Halldórsson and Skjøtt-Larsen, 2004). One example is when an LSP invests in a fleet with special handling equipment to transport products of a complex nature for a particular shipper. Such customization, however, also implies that the invested assets are dedicated to one relationship but obsolete in another, which may induce opportunistic behaviour (Williamson, 1981). To mitigate such behaviour, partners tend to agree on long-term contracts to safeguard their relationship (Huo et al., 2017). Long-term contracts can also minimize transactional costs due to reduced uncertainty (Brekalo and Albers, 2016) and protect LSPs from sunk costs in case shippers consider terminating the agreement (Huo et al., 2018). Accordingly, we single out asset specificity, customization and contract duration as variables characterizing relation-specific mechanisms.

Knowledge-sharing mechanisms - RV also holds that in order for the collaborating partners to create competitive advantage, they should intensify their interfirm knowledge sharing (Dyer and Singh, 1998), emphasized in learning from one another and joint learning (Halldórsson and Skjøtt-Larsen, 2004). This is based on the notion that alliances are one of the most important sources of new ideas, as they allow both partners to generate relational rents through superior knowledge-sharing routines (Dyer and Singh, 1998). Knowledge sharing also comprises exchanging personnel, such as when experts are employed full time at the other partner's facility (Brekalo and Albers, 2016). These measures safeguard shipper-LSP relationships because they enhance transparency, minimize information asymmetry and limit self-seeking interest (Yuan et al., 2018). To further facilitate knowledge sharing, partners tend to integrate their IT systems via diverse interfaces, such as vendor-managed inventory and electronic data interchange (Huo et al., 2017). These interfaces enable control over LSPs and lead to even better transparency between the partners (Jazairy et al., 2017). Accordingly, we single out learning exchange, personnel exchange and IT integration as variables characterizing knowledge-sharing mechanisms.

Table 1 reviews each of the specified variables under the two collaboration mechanisms in close shipper-LSP relationships.

\section{Green logistics practices}

The green logistics literature has identified and grouped different types of GLPs based on their diverse natures (Cf. Colicchia et al., 2013; Martinsen and Huge-Brodin, 2014; Sureeyatanapas et al., 2018). The most recognized GLPs are green modal shifts, green transport management, green logistics systems, green vehicle technologies, eco-driving, alternative fuels, green warehousing and green packaging. Each is described and exemplified in Table 2.

\section{Collaboration mechanisms for GLPS}

In this section, we provide possible suggestions onto how the two types of collaboration mechanisms may facilitate the different GLPs described above, based on the literature.

Green modal shifts - Intermodal platforms represent a typical example of modal shifts for the environment (Martinsen and Huge-Brodin, 2014). Due to the highly complex and 


\begin{tabular}{|c|c|c|c|}
\hline Variable & Description & References & Collaboration \\
\hline \multicolumn{3}{|c|}{ Relation-specific mechanisms } & reen \\
\hline $\begin{array}{l}\text { Asset specificity } \\
{[1]}\end{array}$ & $\begin{array}{l}\text { Medium/high level of asset specificity with } \\
\text { investments (tangible and non-tangible) made } \\
\text { by the LSP to fulfil shipper's requirements }\end{array}$ & $\begin{array}{l}\text { Brekalo and Albers (2016), } \\
\text { Halldórsson and Skjøtt-Larsen (2004), } \\
\text { Huo et al. (2018) }\end{array}$ & logistics \\
\hline Customization & $\begin{array}{l}\text { Solutions require advanced LSP skills and are } \\
\text { tailor-made to specifically suit the shipper's } \\
\text { demands }\end{array}$ & $\begin{array}{l}\text { Brekalo and Albers (2016), } \\
\text { Halldórsson and Skjøtt-Larsen (2004) }\end{array}$ & 427 \\
\hline $\begin{array}{l}\text { Contract } \\
\text { duration }\end{array}$ & $\begin{array}{l}\text { Long-term contracts between the partners, with } \\
\text { a focus on creating strategic win-win alliances }\end{array}$ & $\begin{array}{l}\text { Halldórsson and Skjøtt-Larsen (2004), } \\
\text { Huo et al. (2017) }\end{array}$ & \\
\hline \multicolumn{4}{|c|}{ Knowledge-sharing mechanisms } \\
\hline $\begin{array}{l}\text { Learning } \\
\text { exchange }\end{array}$ & $\begin{array}{l}\text { Knowledge and experience are frequently } \\
\text { exchanged between the partners, characterized } \\
\text { by learning from one another and joint learning }\end{array}$ & $\begin{array}{l}\text { Brekalo and Albers (2016), } \\
\text { Halldórsson and Skjøtt-Larsen (2004), } \\
\text { Yuan et al. (2018) }\end{array}$ & \\
\hline $\begin{array}{l}\text { Personnel } \\
\text { exchange }\end{array}$ & $\begin{array}{l}\text { Personnel are exchanged between the partners, } \\
\text { such as when the LSP's personnel are stationed } \\
\text { full time at the shipper's premises }\end{array}$ & $\begin{array}{l}\text { Brekalo and Albers (2016), } \\
\text { Halldórsson and Skjøtt-Larsen (2004) }\end{array}$ & \\
\hline IT integration & $\begin{array}{l}\text { IT systems of the two partners are highly } \\
\text { integrated, using interfaces such as electronic } \\
\text { data interchange and vendor-managed } \\
\text { inventory }\end{array}$ & $\begin{array}{l}\text { Brekalo and Albers (2016), } \\
\text { Halldórsson and Skjøtt-Larsen (2004), } \\
\text { Jazairy et al. (2017) }\end{array}$ & $\begin{array}{r}\text { Table 1. } \\
\text { Collaboration } \\
\text { mechanisms in close } \\
\text { logistics relationships }\end{array}$ \\
\hline
\end{tabular}

customizable nature of these platforms (Khaslavskaya and Roso, 2019), LSPs are likely to refrain from investing in them unless shippers share the risks of such investments over long contracting periods (Eng-Larsson and Norrman, 2014). Jointly treating assets related to these platforms (e.g. locomotives, terminals) as relation-specific assets (instead of mere firm-specific assets) has been proposed as a key contributor to their success (Khaslavskaya and Roso, 2019; Monios and Bergvist, 2016). The literature also seems in favour of knowledge sharing for facilitating these platforms. Monios and Bergvist (2016), for instance, contend that sea-road-rail platforms prosper in trustful and collaborative environments, ascribing the denominator of their operational success to interorganisational "learning, knowledge sharing, coordination and complementarity" (p. 548). Extensive and continuous information exchange between shippers and LSPs, backed by integrating their IT systems, may uphold the success of intermodal platforms, as these measures reduce unpredictability of arrival times and increase transport efficiency (Choy et al., 2007).

Green transport management - Tight delivery windows imposed by shippers on LSPs impede them from fully utilizing trucks or optimizing routes (Sanchez-Rodrigues et al., 2010) due to increased frequency of trips and reduced quantities in each trip (Danloup et al., 2015). LSPs, therefore, may require access to shippers' operational spreadsheets, warehouse locations and customer delivery points to optimize routes, consolidate shipments and increase fill rates. LSPs might exploit their bargaining position by disclosing shippers' information (Poppo et al., 2008), unless LSPs apply relation-specific assets (Huo et al., 2018). These assets can be intangible in this case, such as when LSPs invest in human expertise and tailor them to optimize shipper-related deliveries. To avoid the risk of sunk costs in case shippers terminate the contract, LSPs are likely to request shippers' long-term commitment to safeguard these investments. Joint shipper-LSP efforts on updating shipping schedules, reallocating transport capacities and extending lead times have been suggested as effective measures to increase fill rates (Rogerson and Santén, 2017), stressing the potential effect of knowledge-sharing mechanisms on this GLP. IT integration may also play a role, as it enables jointly monitoring/ 


\section{IJPDLM 51,4}

\section{8}

Green

transport management

Green logistics systems

Green modal shifts

Description and examples of practices

Shifting to a more environmentally friendly transport mode. Intermodal platforms support these shifts, since many delivery points are not located at harbours/railway stations. These platforms facilitate shifting across two modes (e.g. road-to-rail), or more (e.g. sea-road-rail), such as dry ports Managing transport activities to reduce their environmental impact. Comprises practices such as scheduling of freight frequency, selection of vehicle size, consolidation of shipments, milk-run distributions, increasing fill rates, reducing empty running, and route optimization

Has a broader scope than green transport management. Comprises large-scale projects such as redesigning distribution networks (e.g. changing location of nodes for decreased environmental impact) and operationalizing urban consolidation centres (often seen as part of "city logistics")

Green vehicle technologies

Using the latest technological advancements for reduced fue consumption in different transport modes. Covers operating intelligent autonomous vehicles, utilizing information from connected vehicles, vehicle design for less air resistance, more efficient engines, and stopping with engines off

Eco-driving

Driving techniques to decrease fuel consumption and emissions, characterized by (1) behavioural skills (e.g. acceleration/deceleration, adjusting driving speed, idling) and (2) supporting measures (e.g. training programs for drivers, invehicle feedback devices to improve eco-driving performance)

Table 2. Green logistics practices (GLPs)
Alternative fuels

Shifting from conventional fossil fuels (e.g. diesel, petrol) to more renewable and less fossil-based ones (e.g. biofuels, electric engines). Also covers localization of refuelling stations, due to the limited travel range with alternative fuelpowered vehicles

Green Comprises supplying warehouse buildings with clean and

warehousing

renewable energy sources (e.g. solar, wind), decreasing energy use in warehouse buildings and equipment, operating warehouses in an efficient and conscious green manner

Green Comprises packaging design, reduction, reuse and recycling packaging Comprises packaging design, reduction, reuse and recycin
for the environment. Also covers optimized stacking of packages in trucks to increase transport efficiency
References

Eng-Larsson and Norrman (2014), Martinsen and HugeBrodin (2014), Monios and Bergvist (2016)

Martinsen and Huge-Brodin (2014), Rogerson and Santén (2017), Sureeyatanapas et al. (2018)

Awasthi et al. (2016), Björklund and Johansson (2018), Evangelista (2014),

Martinsen and Huge-Brodin (2014)

Björklund and Forslund (2018), Colicchia et al. (2013), Kavakeb et al. (2015),

Martinsen and Huge-Brodin (2014)

Evangelista (2014), Fors et al. (2015), Goes et al. (2020),

Huang et al. (2018),

Martinsen and Huge-Brodin (2014)

Anderhofstadt and Spinler (2019), Evangelista (2014), Martinsen and Huge-Brodin (2014)

Centobelli et al. (2017), Colicchia et al. (2013), Goh (2020), Martinsen and HugeBrodin (2014)

Molina-Besch and Pålsson (2014), Sureeyatanapas et al. (2018), Verghese and Lewis (2007)

analysing information from connected vehicles, such as their position and speed, which can lead to optimized traffic flows (Guerrero-Ibanez et al., 2015; Guler et al., 2014).

Green logistics systems - Urban consolidation centres, a concrete example of these systems, are associated with extensive risks and uncertainties (Awasthi et al., 2016), due to their reliance on idiosyncratic assets including trained personnel, dedicated fleets and customized facilities (de Marco et al., 2014). Acquiring these assets may necessitate forming long-term risk-sharing contracts between shippers and LSPs to safeguard the investments made. Codevelopment of data-centric systems, a form of IT integration, may harmonize shippers and LSPs when operating these centres (de Souza et al., 2013). Here, data mining could enable exploiting various streams of data (e.g. past orders, seasonal demands, traffic conditions) (de Souza et al., 2013), allowing both actors to make data-driven decisions at strategic, tactical and operational levels, while offering them prescriptions to optimize. Personnel of shippers' and LSPs' firms can also be stationed at these centres, which may foster jointly organising 
last-mile deliveries (Cleophas et al., 2019), attending training programs for correct implementation (Triantafyllou et al., 2014) or simply learning from LSPs' expertise (Awasthi et al., 2016). All these measures are expected to enhance transparency and reduce information asymmetry in shipper-LSP relations, implying that both collaboration mechanisms are potential facilitators for this GLP.

Green vehicle technologies - Hofmann et al. (2018) predicted a negative impact of oil price fluctuations on LSPs' financial performance, which might redirect their investment strategies towards modern, less fuel-consuming vehicles. However, such vehicles can be expensive; Kavakeb et al. (2015) found that green autonomous vehicles, which can replace trucks in ports, are almost five times more expensive than conventional trucks. As LSPs' investment capacity is often hampered by tight profit margins (Piecyk and Björklund, 2015), purchasing those vehicles may require long-term contracts with shippers. LSPs may designate their modern fleets as relationspecific assets, yet shippers may not share the risks of such investments unless customized services are simultaneously requested (Jazairy, 2020). Knowledge sharing may also facilitate this GLP; Björklund and Forslund (2018) presented an example where a shipper partook in testing electric hybrid trucks through collaborating with several actors, including an LSP. These tests aimed to operationalize silent night-time deliveries within cities, hence lowering emissions through decreased daytime congestion. One technology utilized GPS locations of quiet zones to automatically turn off radio devices in trucks and lower their beeping noise when backing up. Testing such technologies could be enabled by IT integrations, with data obtained from vehicles' connectivity shared among the actors to enable timely decision making.

Eco-driving - Eco-driving is generally seen as a low-cost measure (Huang et al., 2018; Zavalko, 2018), and it can be argued that no significant upfront investments or specific assets are needed to facilitate it. However, investing in training programs to coach eco-driving skills may or may not pay off, depending on whether such training is applied to the entire fleet (Goes et al., 2020) or designed on an effective, long-term basis (Huang et al., 2018). Also, acquiring supportive in-vehicle devices (e.g. fuel consumption displays, feedback systems) (Fors et al., 2015) may require significant investments, which LSPs may not delve into due to the risk of sunk costs - especially if applied to entire fleets. Hence, it can be presumed that relation-specific mechanisms may facilitate comprehensive, effective and long-lasting ecodriving programs alongside their supportive in-vehicle devices. Eco-driving programs should include monitoring drivers' skills, since merely learning these skills does not guarantee transferring them into everyday practice (Zavalko, 2018). Monitoring covers fuel consumption, speed, acceleration/deceleration, idling and traffic conditions (Huang et al., 2018). This information can be harnessed in the LSP's system and integrated with the shipper's, potentially enabling both to jointly observe/improve eco-driving performance.

Alternative fuels - After examining several LSPs in Europe, Jazairy (2020) found instances where LSPs treated biofuel-powered fleets as relation-specific assets, with their capacity to invest in them materializing only after securing five-year contracts with shippers, and these were attainable only when customized services were offered. However, there is a lack of knowledge on whether shippers share the same view on the matter. The limited range of alternative fuelpowered vehicles and the insufficient refuelling infrastructure are seen as major barriers to their operationalization (Erdoğan and Miller-Hooks, 2012). To set optimal locations for refuelling stations, Anderhofstadt and Spinler (2019) called for collaboration between truck manufacturers, infrastructure operators, policymakers and LSPs. Since LSPs' routes are typically constrained by the locations of shippers' customers (Wolf and Seuring, 2010), involving shippers in such collaborations could make sense. This can be achieved by exchanging knowledge/personnel with shippers to optimize routing plans in conjunction with the locations of refuelling stations.

Green warehousing - To maintain their flexibility, LSPs tend to lease warehousing facilities instead of buying their own. However, the state and environmental standards of current facilities in the leasing market constrain their choices (Grant et al., 2017). This makes
Collaboration mechanisms for green logistics 
IJPDLM 51,4

430

facilitating green warehousing solutions contingent on LSPs' investments. Goh (2020) argued that it is "unreasonable" to expect LSPs to enter into such investments without long-term contracts, though shippers might not commit to those unless unique and value-added services are desired (Jazairy, 2020). Knowledge-sharing mechanisms may also support this GLP; reaching joint emission reduction targets in warehouses calls for shippers to work jointly with LSPs to track the emissions related to their operations (Goh, 2020). Such joint work invites exchanging personnel (Brekalo and Albers, 2016) and integrating IT systems (Jazairy et al., 2017) to reduce information asymmetry and enhance transparency. Moreover, a new stream of research predicts utilizing emergent IT tools (e.g. Internet of Things, artificial intelligence) for improved green warehousing (Rajahonka et al., 2019; Wahab et al., 2018). The Internet connectivity embedded in such tools may allow integrating them with the systems of shippers and LSPs to facilitate monitoring/improving green warehousing applications.

Green packaging - Shippers tend to engage in green packaging through eco-design to enhance their green image, given that those packages are applied to their products (Sureeyatanapas et al., 2018). In turn, excess amounts of packaging lower transport efficiency by increased weight/space of transported goods (Molina-Besch and Pålsson, 2014), incentivizing LSPs to engage in green packaging to minimize transport costs (Bask et al., 2018). Green packaging is often described as an innovative initiative that requires both actors to collaborate (Verghese and Lewis, 2007; White et al., 2015). In these collaborations, the commitment of both actors is advised to assess, on a long-term basis, the win-win potentials of green packaging as well as the associated investments/risks (Verghese and Lewis, 2007). Also, the actors are advised to share knowledge to jointly identify ways to extend lead times, which may allow LSPs to redesign packages for better stacking and loading in trucks (Lun et al., 2015; Rogerson and Santén, 2017). Integrating IT systems may also support that end, as it enables both actors to assess the amounts of waste across the supply chain (Verghese and Lewis, 2007).

\section{Theoretical model}

Figure 1 depicts our theoretical model, which shows the proposed influences of the two types of collaboration mechanisms on the eight GLPs. We will examine this model separately on

\section{Collaboration mechanisms}

Green logistics practices

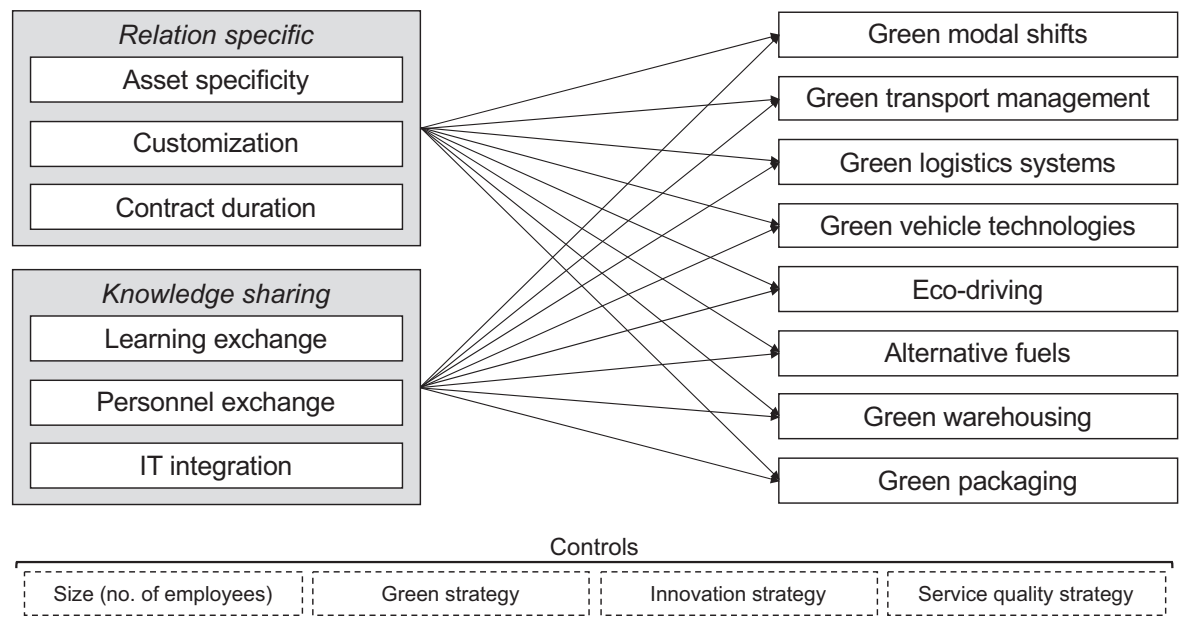

Figure 1.

Theoretical model

Note(s): The model will be tested separately on shipper and LSP samples 
shipper and LSP samples to reveal whether they share the same view on these influences, as per our research questions. This understanding would enable shipper and LSP practitioners to fit their relationships to the desired GLPs (i.e. "fit for purpose"). However, portraying mechanism-GLP associations in this manner might not capture the complex nature of logistics relationships. Shippers' decisions to collaborate with LSPs are contingent on the strategic importance of the outsourced logistics functions (Halldórsson and SkjøttLarsen, 2004). Here, different logistics strategies may drive collaboration and facilitating GLPs. If both statements hold true, a seemingly close association between collaboration mechanisms and GLPs may be due to both being driven by the same underlying strategies. This necessitates adding variables related to strategy as control variables. According to RV, shippers and LSPs collaborate to obtain valuable and unique competencies (Dyer and Singh, 1998; Huo et al., 2017). These competencies emerge mainly by accessing, through collaboration, new innovation capabilities and high quality of service (Lai et al., 2008; Sinkovics et al., 2018). Hence, we incorporate innovation strategy and service quality strategy (in a relation-specific context) as control variables in our model (Figure 1). We also include green strategy as a third control variable, since relationships that are built upon green strategies are likely to influence GLPs but also to be associated with collaboration. We also control for size (in terms of number of employees) because it is commonly treated as a control variable in supply chain management studies.

\section{Methods \\ Survey design}

This study relies on a web-based survey on green logistics in shipper-LSP relationships. To match the buying and selling roles of shippers and LSPs, two "mirrored" versions (one for each) were designed using Qualtrics XM. Questions were asked in a relationship-specific context. First, respondents were requested to specify an ongoing business relationship with an environmentally conscious shipper/LSP (to enable detecting a variety of GLPs). This was followed by three questions on the importance of logistics strategies (green "Gr-Stra", innovation capability "Innov-Stra" and service quality "Qual-Stra") when formulating this relationship (based on a Likert scale of 1 , low importance, to 5 , high importance). Then, six questions were asked to describe the extent of collaboration in this specific relationship, one question for each variable under the two types of collaboration mechanisms (Figure 1). We used five-point bipolar scales for these questions, with one end reflecting arm's-length arrangements and the other end reflecting collaborative partnerships (based on Table 1). Last, respondents were requested to estimate (on a scale of 1 , very low, to 5 , very high) the extent of implementing each of the eight GLPs in the specified relationship. Each question had the option "inapplicable" or could be left unanswered. The survey instrument can be found in Appendix. In line with Forza (2002), we piloted the instrument by sending it to three experts in the logistics industry to ensure (1) clarity of the questions, (2) applicability of the scales and (3) minimized risk of leading the respondents. The instrument was modified in line with the experts' comments.

\section{Data collection}

Two groups of firms were targeted: shippers and LSPs. We extracted a list for each group operating in Sweden using the Retriever database (https://www.retriever-info.com). The key selection criterion for shippers was belonging to industries that are typically associated with transporting/storing goods, since those are likely to purchase logistics services from LSPs. We excluded firms with revenues under $100 \mathrm{~m} \mathrm{SEK}(\sim 10 \mathrm{~m} €)$, since it is mainly large shippers who attend to green concerns when purchasing logistics, due to both their larger impact on the 
IJPDLM 51,4

environment and their inclination to include green criteria in their strategies (Björklund, 2011). A population of 1,231 shippers was obtained. In turn, the main criterion for selecting LSPs is providing logistics services. Small LSPs were not excluded (unless their revenues were below $1 \mathrm{~m}$ SEK), since even those offer green services, and their client portfolios usually comprise large shippers (Jazairy, 2020). This yielded a population of 873 LSPs.

It is advised to use stratified random sampling to enhance representativeness of the sample, which also enables dividing the population based on meaningful criteria such as firm size (Forza, 2002). To grant large firms, which are fewer in number but have a bigger impact on the environment, a larger chance of inclusion in our sample, we divided the population into strata based on firms' revenues and performed random sampling for each stratum (Table 3). This resulted in a total of 1,000 firms: 500 shippers and 500 LSPs. To obtain reliable responses, we contacted each firm by phone to reach respondents (preferably managers) who are familiar with the logistics buying/selling process and in contact with their logistics partners. We managed to distribute our web-based survey to 183 shippers and 290 LSPs; the rest did not express interest in participation or could not be reached. A total of 331 firms (169 shippers; 162 LSPs) answered the survey after two rounds of reminders. Data were collected between mid-November 2018 and mid-February 2019. The final dataset contains a sample of logistics buyers and providers in the Swedish logistics market that is both representative (due to stratified random sampling, coverage of the entire population and a reasonably high response rate) and well-balanced (due to the similarity in the number of responses between the two groups). Shippers' respondents are mainly purchasing and supply chain managers, whereas LSPs' respondents are mainly top executives, environmental directors and sales managers. Shipper firms in the dataset pertain to four main industries: manufacturing, wholesale and retail, food and infrastructure - with almost half of them in the manufacturing industry. We performed independent sample $t$-tests to detect whether belonging to any of these industries may influence the GLPs (see Findings).

\section{Data analysis}

We tested the data for skewness and kurtosis to assess normality: all values fell below the critical value of \pm 2 suggested by George and Mallery (2010). Using Statistical Product and Service Solutions (SPSS) 23, we applied exploratory factor analysis (EFA) to preliminarily assess the convergent and discriminant validity of the two collaboration mechanisms constructs. The extraction method was principal component analysis with Varimax rotation, chosen because the extracted components were not correlated. The performed EFA revealed the presence of two components with initial eigenvalues exceeding 1.0, explaining $30.9 \%$ and $26.4 \%$ of the variance in the rotated solution, respectively (Table 4 ). Also in the rotated solution, all the variables reported strong loadings (i.e. above 0.4 , as suggested by Hair et al., 2010) on the construct that they were supposed to measure, and much lower loadings on the construct they were not supposed to measure - endorsing both convergent and discriminant validity of the

\begin{tabular}{|c|c|c|c|c|c|c|c|c|}
\hline \multirow[b]{2}{*}{ Category } & \multicolumn{2}{|c|}{$\begin{array}{c}\text { Revenues } \\
\text { (mSEK) }\end{array}$} & \multirow[b]{2}{*}{ Population $(N)$} & \multirow[b]{2}{*}{ Selected $(N)$} & \multicolumn{2}{|c|}{$\begin{array}{c}\text { Revenues } \\
\text { (mSEK) }\end{array}$} & \multirow[b]{2}{*}{ Population $(N)$} & \multirow[b]{2}{*}{ Selected $(N)$} \\
\hline & From & To & & & From & To & & \\
\hline & & & Shippers & & & & LSPS & \\
\hline 1 & 10,000 & $\infty$ & 53 & All & 1,000 & $\infty$ & 29 & All \\
\hline 2 & 5,000 & 9,999 & 57 & All & 250 & 999 & 110 & All \\
\hline 3 & 1,000 & 4,999 & 400 & 195 & 50 & 249 & 355 & 181 \\
\hline \multirow[t]{2}{*}{4} & 100 & 999 & 721 & 195 & 1 & 49 & 379 & 180 \\
\hline & & Total & 1,231 & 500 & & Total & 873 & 500 \\
\hline
\end{tabular}

Table 3.
Stratification logic 
two constructs. To test reliability of the two constructs, Cronbach's $\alpha$ was checked. Hair $e t$ al. (2010) recommend accepting values of 0.7 and above and rejecting values under 0.5. The relation-specific construct adequately passed this test, whereas the knowledge-sharing construct was just above the critical threshold (Table 4). However, low values are common for constructs with a small number of variables (i.e. fewer than 10) (Briggs and Cheek, 1986). Hence, reliability of the two collaboration mechanisms constructs was deemed satisfactory.

Since the two constructs are based on theoretical grounds, we performed confirmatory factor analysis (CFA) to further confirm their convergent and discriminant validity, using Analysis of Moment Structures (AMOS) 26. Each variable was linked to its corresponding construct, and the correlation between those constructs was freely estimated. The model fit indices are as follows: $\chi^{2}=13.7$, degrees of freedom $=8$, RMSEA $=0.046$, CFI $=0.971$, TLI $=0.924$ - indicating an acceptable model fit (Brown, 2015). In the model, most of the factor loadings $(\lambda)$ were greater than 0.50 and $t$-values greater than 2.0, signalling sufficient convergent validity (Bollen, 1989). However, lower loadings were detected with the variables "customization" (0.48) and "personnel exchange" (0.33), representing a fair level of support for the former, and a low, yet acceptable, level of support for the latter (Tabachnick and Fidell, 2007). The reason for the low loading on "personnel exchange" may relate to its contextual nature; some firms exchange personnel for reasons beyond knowledge sharing, implying that its relation to the other variables under this construct can be somewhat lower. However, since it is viewed as a meaningful way to reflect knowledge sharing (Brekalo and Albers, 2016), we decided to keep it. To further confirm discriminant validity, we constrained our CFA model by fixing the correlation between the two constructs to 1.0. This model was then compared with the original nonconstrained model (where the correlation between the constructs was freely estimated). A high level of significance $(\phi<0.01)$ was reported for the difference between $\chi^{2}$ values of the two models - indicating a solid discriminant validity (Bagozzi et al., 1991).

We performed multiple regression analysis (MRA) to detect associations between the two collaboration mechanisms constructs (independent variables) resulting from the EFA and the eight identified GLPs (dependent variables). To enable comparing between shippers' and LSPs' viewpoints (RQ2), we split the sample into two subsamples, one for each group. We thus performed a total of 16 MRAs. The MRAs included our four control variables: size (logarithmic value for number of employees) and strategy (Gr-Stra, Innov-Stra, Qual-Stra). The number of missing values varied between the GLPs due to the relationship-specific design of the survey (see $n$ values in Tables A1 and A2 in Appendix). To counter this in the MRAs, we replaced the missing values with mean values. This was done with caution; if there is a reason to believe that the missing values are likely to be extreme values, replacing them with mean values is not recommended (Acock, 2005) - but there was no reason to believe this with our dataset. However, replacing with mean values can reduce the reported $\beta$ values

\begin{tabular}{|c|c|c|c|}
\hline & \multicolumn{2}{|c|}{ Factor loadings } & \\
\hline & Relation specific & Knowledge sharing & \\
\hline Asset specificity & 0.802 & 0.286 & \\
\hline Customization & 0.745 & -0.034 & \\
\hline Contract duration & 0.744 & 0.109 & \\
\hline Learning exchange & 0.309 & 0.659 & \\
\hline Personnel exchange & 0.058 & 0.617 & \\
\hline IT integration & -0.012 & 0.821 & Table 4. \\
\hline Initial eigenvalue & 2.249 & 1.185 & Exploratory factor \\
\hline Variance explained (in rotated solution) & 30.859 & 26.383 & analysis (rotated \\
\hline Cronbach's $\alpha$ & 0.671 & 0.527 & solution: Varimax) \\
\hline
\end{tabular}
mechanisms for green logistics
Collaboration 
IJPDLM

51,4

(Acock, 2005) and slightly increase the significance level, as the sample may appear larger than it actually is. Hence, we considered the associations with a significance of $p<0.01$ as "strongly supported", whilst those with a significance of $p<0.05$ as "marginally supported" calling for extra caution in their interpretation.

\section{Findings}

Tables A1 and A2 in Appendix show descriptive statistics and correlation matrices for the variables and constructs used in our analysis, separately for shippers and LSPs. Tables 5 and 6 report MRAs that treat each GLP as a dependent variable, and the collaboration mechanisms constructs "relation specific" and "knowledge sharing" as independent variables. The models in Tables 5 and 6 show the explanatory power $\left(R^{2}\right)$ for each dependent variable, with the highest values for both actors on green vehicle technologies (shippers: 0.404, LSPs: 0.207), and the lowest value for shippers on green packaging (0.163) and for LSPs on green transport management $(0.055)$. Note that the $R^{2}$ values are consistently higher for shippers than for LSPs. This appears to be largely driven by the control variable Gr-Stra, since the $\beta$ values for this variable are also consistently higher for shippers. A green strategy is thus a major driver for shippers, and to a lesser extent for LSPs, to facilitate GLPs. Here, shippers might consider all GLPs to be related to their green purchasing strategies, whereas LSPs might possess a more detailed view by treating some GLPs as means to lower costs or attain other operational benefits. Out of the other control variables, firm size has a small but significant impact on green warehousing (shippers), Qual-Stra has a significant negative impact on three GLPs (one for shippers, two for LSPs), whereas Innov-Stra does not have a significant impact on any GLP (Tables 5 and 6 ). The $F$-values are significant in all regression models (except for green transport management for LSPs), suggesting that our data fit the models well.

In Tables 5 and 6, we can see that the relation-specific construct significantly explains the variance in nine out of sixteen MRAs (five for shippers, four for LSPs). Knowledge sharing, in turn, significantly explains the variance in six MRAs (three for each actor), by which the associations vary depending on the actor.

As mentioned in Methods, we performed $t$-tests to detect whether shippers' affiliation with any of the four industries can influence the GLPs. These tests indicated that (1) shippers within the food industry tend to engage significantly further in the majority of GLPs compared to those within the manufacturing and wholesale and retail industries; and (2) shippers within the infrastructure industry tend to engage significantly further in a few GLPs compared to those within the manufacturing and wholesale and retail industries. While these findings may corroborate previous research asserting that shippers in the food industry are more scrutinized due to the sensitivity of their products (Jazairy and von Haartman, 2020), or may even offer novel insights relating to the infrastructure industry, the limited number of responses obtained for each of these two industries ( 10 per GLP) constrained us from using this information further or drawing solid conclusions based on it. However, we see a potential in carrying out surveys with a larger number of shippers in the food and infrastructure industries as a promising area for further research.

\section{Discussion}

Our findings generally indicate that both shippers and LSPs acknowledge the importance of both types of collaboration mechanisms in facilitating the GLPs (Figure 2). Our findings also suggest that (1) most GLPs may require only one type of collaboration mechanisms; (2) relation-specific mechanisms have a stronger effect on GLPs compared to knowledgesharing mechanisms; (3) some GLPs might not require collaboration in the first place (i.e. 


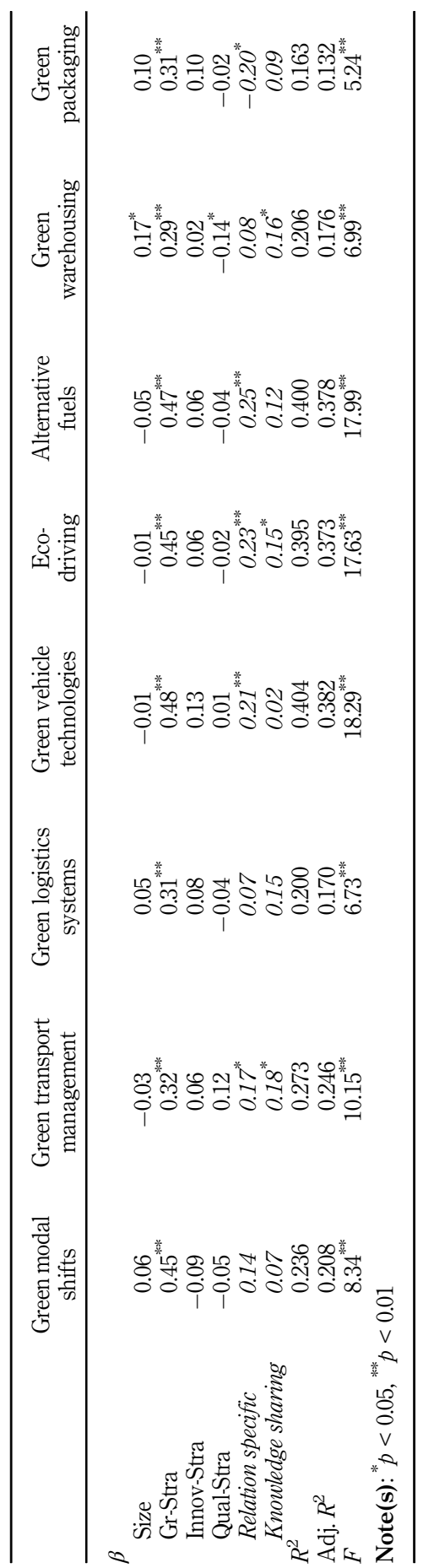

Collaboration mechanisms for green logistics

435

Table 5. Multiple regression analysis (Shippers) 
IJPDLM

51,4

\section{6}

Table 6.

Multiple regression analysis (LSPs)

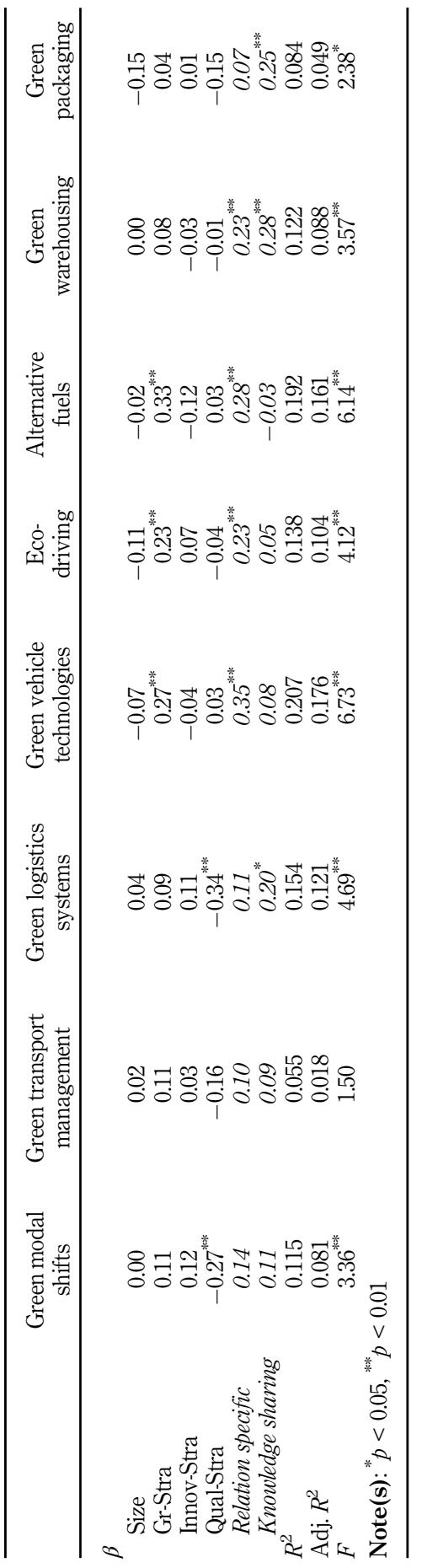




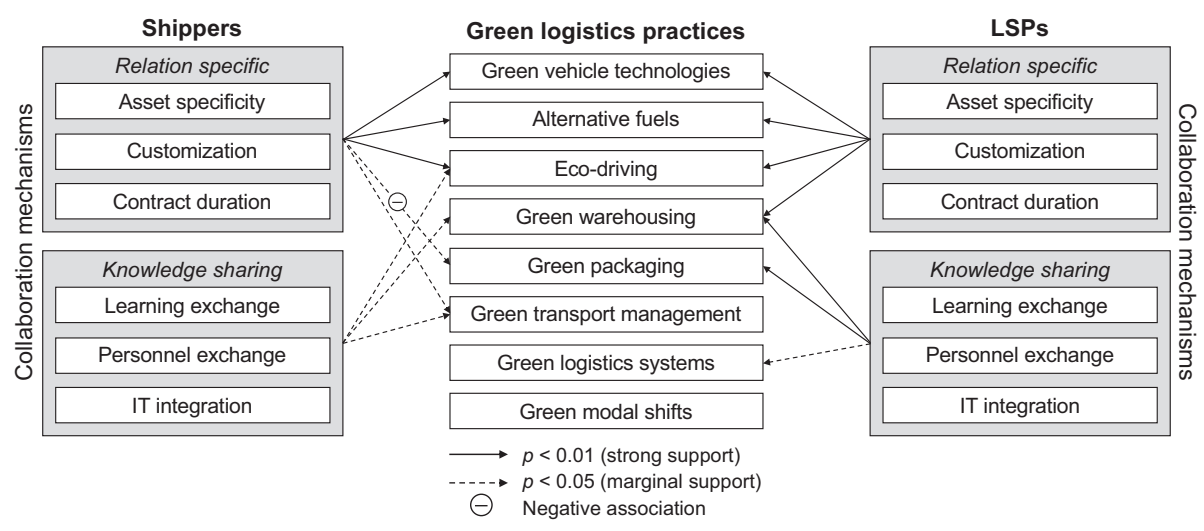

Collaboration mechanisms for green logistics

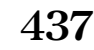

Figure 2.

Verified model with significant relationships

arm's-length arrangements might suffice for them); and (4) there is a great similarity between shippers' and LSPs' views on "fleet-oriented" GLPs (while their views took contrasting forms for others). Looking at the impact of relation-specific mechanisms on the first three GLPs (Figure 2), our findings point to the likelihood of investing in relation-specific assets for multiple GLPs at the same time. For instance, investing in modern, alternative fuel-powered vehicles may subsume investing in green vehicle technologies (e.g. design for less air resistance) or in-vehicle devices to support eco-driving (e.g. fuel consumption displays), as all these attributes could be spotted in the same vehicles.

A positive effect of relation-specific mechanisms on green vehicle technologies as well as alternative fuels was supported from both actors' viewpoints. This may indicate that both actors recognize modern green fleets, whether powered by alternative fuels or backed by technologies for reduced fuel consumption, as relation-specific assets. This also suggests that investing in such fleets may be particularly feasible for LSPs when long-term contracts are secured, as is typical under customized settings. Although Jazairy (2020) revealed the LSPs' viewpoint on the matter, our findings contribute by adding the shippers' viewpoint. Shippers might have recognized the costly nature of these fleets together with the LSPs' incapacity to acquire them on their own (possibly due to LSPs' tight margins - Piecyk and Björklund, 2015); thus, they decided to share investment risks for their facilitation. Overall, the GLPs green vehicle technologies and alternative fuels share mutual features, being more concrete and vehicle-oriented, which could have made them more obvious to agree on while designing the contract. Hence, it can be proposed that shippers and LSPs may employ relation-specific mechanisms when GLPs of such a concrete nature are desired.

In a similar vein, the effect of relation-specific mechanisms on eco-driving was strongly supported from both actors' views, added to a marginal support of knowledge sharing from the shippers' view. The first link may suggest that both actors consider LSPs' investments in training programs or supportive in-vehicle devices as means to facilitate eco-driving noting that these investments pay off when applied to entire fleets (Goes et al., 2020), or designed on a long-term basis (Huang et al., 2018). The second link may indicate the shippers' willingness to monitor eco-driving performance of their related deliveries and to integrate such data into their systems - possibly for reporting purposes. LSPs, in turn, may consider themselves as "eco-driving experts", thus not requiring knowledge sharing with shippers for this GLP.

Our findings suggest that LSPs view green warehousing as a GLP that not only requires relation-specific mechanisms but also high degrees of knowledge sharing. The first link may be attributed to LSPs' frequent calls for shippers' long-term commitments to secure the 
IJPDLM 51,4

paybacks of green warehousing investments, as reported in the literature (Goh, 2020; Jazairy, 2020). The second link may signal the LSPs' desire to minimize their warehousing emissions through working closely with shippers. Yet, and perhaps to LSPs' disappointment, we find that shippers share the LSPs' view on this GLP only on the knowledge-sharing part - and only with marginal support. This may suggest that shippers, despite LSPs' calls, still consider LSPs to be the ones in charge of green warehousing investments (possibly because they concern LSPs' facilities). As this GLP is associated with a negative impact of quality strategy amongst shippers (Table 5), their doubt about the capability of emergent green warehousing solutions in delivering the desired service quality might be the case - making shippers even more reluctant to share investments risks for this GLP. Instead, our findings suggest that shippers would rather collaborate through knowledge sharing to minimize warehousing emissions, which can be seen as a partial response to LSPs' calls.

Interestingly, a negative effect of relation-specific mechanisms is found on green packaging with shippers, opposed by a positive effect of knowledge sharing on the same GLP with LSPs. Such a stark contrast between the actors' views could be traced to their actor-specific tasks for this GLP. Shippers are likely to consider green packaging as an eco-design task, where they select environmentally friendly materials/labels for their products to enhance their green image (Sureeyatanapas et al., 2018), making collaboration with LSPs somewhat irrelevant. As for LSPs, they might consider green packaging as a task related to better handling/stacking in trucks (which could also lower transport costs). For this task, LSPs are likely to seek shippers' involvement through knowledge sharing to understand the weights and volumes of transported packages - albeit shippers do not share their view on the matter.

The contrast between the two actors' viewpoints extends to green transport management, for which neither type of collaboration mechanisms was supported with LSPs, whilst both were marginally supported with shippers. This may signal the LSPs' confidence in their own expertise for optimizing routes and increasing fill rates. For shippers, this finding may suggest their willingness to collaborate both ways to benefit from, for instance, LSPs' consultancy expertise (i.e. human assets), which could be tailored to optimize shipper-related deliveries - a service that LSPs might consider adding to their offerings.

When a larger-scale GLP is in question, the situation differs: our findings suggest that shippers consider neither type of collaboration mechanisms as a means to facilitate green logistics systems, whilst a marginal support is associated with knowledge sharing for this GLP among LSPs. This could put into question the need of shippers' legal enforcements for ventures embedded under this GLP, such as urban consolidation centres. Due to the largescale nature of these centres and their orientation to serve multiple shippers, LSPs might share the risks of their investments with actors beyond a specific shipper, such as local authorities (Björklund and Johansson, 2018). Note the negative effect of quality strategy on this GLP amongst LSPs (Table 6), suggesting that consolidating shipments, in those centres, might harm quality measures such as lead times, which could make LSPs even more hesitant to request shippers' relation-specific commitment for them. In turn, the LSPs' seeming need of knowledge sharing with shippers on this GLPs conforms with the studies advising both to jointly run data mining techniques or plan last-mile deliveries to successfully operate those centres (Cleophas et al., 2019; Triantafyllou et al., 2014) - inviting the shippers' consideration on the matter as well.

Our findings do not support neither type of collaboration mechanisms, from neither actors' views, to facilitate green modal shifts. This is somewhat surprising, given the vast body of literature that attributes the success of intermodal platforms to treating them as relation-specific assets backed by integrated IT systems and extensive knowledge-sharing routines (Eng-Larsson and Norrman, 2014; Khaslavskaya and Roso, 2019; Monios and Bergvist, 2016). This is perhaps due to pre-existent expectations, by both actors, that LSPs are the ones in charge of facilitating green modal shifts, which may have resulted in less 
emphasis on the shippers' involvement. Finding a negative effect of quality strategy on this GLP within LSPs (Table 6) may provide an alternative explanation: shifting modes for the environment could compromise service quality by extending lead times, which might result in LSPs' reluctance to request shippers' collaboration for this GLP.

\section{Conclusions}

By conducting a large-scale survey on 169 shippers and 162 LSPs, we systematically revealed which type of collaboration mechanisms (relation specific, knowledge sharing, or both) is required for facilitating the different types of GLPs - as seen by shippers versus LSPs.

Our findings generally suggest that neither of the actors consistently favour a certain type of collaboration mechanisms for facilitating all types of GLPs (Figure 2). Due to the lack of empirical support for both types of mechanisms with some GLPs (e.g. green modal shifts, green logistics systems), our findings also suggest that not all types of GLPs may require shippers and LSPs to collaborate in the first place - albeit absence of evidence is not necessarily evidence of absence. Although our findings revealed similarities in the actors' views of collaboration mechanisms for some GLPs (e.g. alternative fuels), their views seemed contrasting for others (e.g. green packaging), whereas other GLPs had varying degrees of empirical support (e.g.green warehousing). Hence, this paper contributes to the green logistics literature by challenging the common trend to indiscriminately recommend shippers and LSPs to collaborate for facilitating GLPs, by adding a trilateral distinction into these recommendations based on (1) the collaboration mechanism at play, (2) the actor's perspective (i.e. shipper vs. LSP) and (3) the GLP in question. Future studies may apply these distinctions when investigating collaboration for environmental sustainability within logistics antecedents - rather than treating green logistics as "one bundle" of practices or shippers and LSPs as "one group" of actors.

One of the main findings of this study is that both actors shared the same view of the positive effect of relation-specific mechanisms on facilitating "fleet-oriented" GLPs (i.e. green vehicle technologies, alternative fuels, eco-driving). Although this finding is somewhat expected for LSPs - given that they are the ones in need of shippers' long-term commitments to alleviate the risk of sunk costs when investing in these GLPs - detecting support from the shippers' viewpoint is rather surprising. The literature frequently stresses shippers' lack of willingness to delve into long-term contracts for green purposes (Bask et al., 2018; Sallnäs and Huge-Brodin, 2018), especially with their fear of LSPs' opportunistic behaviour in exploiting their bargaining positions in such contractual situations. Yet, our findings revealed that LSPs' relation-specific assets may have worked as expected in reducing such opportunism (if seen from a TCE viewpoint), enabling both actors to commit to these fleet-oriented GLPs without conflict.

Finding a variation between shippers' and LSPs' views of the role of collaboration mechanisms in facilitating some GLPs (e.g. green logistics systems, green warehousing) carries implications for both the green- and contract logistics fields. For the former, the stronger support for GLPs among LSPs is consistent with the general notion that LSPs are more environmentally committed in their green logistics engagements compared to shippers (Jazairy and von Haartman, 2021; Martinsen and Björklund, 2012; Wolf and Seuring, 2010). This may also indicate that LSPs are more willing to collaborate for GLPs in comparison to shippers, signalling that the lack of shippers' commitment may indeed be a reason for "degreening" logistics networks (Abbasi and Nilsson, 2016; Bask et al., 2018; Sallnäs and HugeBrodin, 2018). Regarding the contract logistics literature, the variation between the actors' views of collaboration mechanisms reinforces their highly contextual nature (Ghosh and Fedorowicz, 2008), suggesting that neither of them is "the best" for maintaining shipper-LSP relationships, especially when environmental gains are at stake. This finding is also coherent
Collaboration mechanisms for green logistics 
IJPDLM 51,4 with RV, which suggests that both types of mechanisms are required to safeguard buyersupplier relationships (Dyer and Singh, 1998).

This paper offers insights to managers at shipper/LSP firms to formulate the right ("fit for purpose") agreement with their logistics partners with respect to the desired GLPs, coupled with other strategic considerations, such as accessed innovation capabilities and quality of service. Managers at shipper/LSP firms may utilize the findings to strategically channel their collaborative efforts towards specifically desired GLPs, using their relationship design and knowledge-sharing routines. Because our findings suggest that long-term contracts play an important role in facilitating several GLPs, a steady logistics market with a low level of uncertainty may be needed to enable shippers to engage in these contracts. This also stresses a need to stabilize the environmental regulations in the logistics industry consistently with shippers' green logistics purchasing demands.

Every study has limitations. While asking respondents about environmentally conscious shippers/LSPs was useful to reveal the extent to which the partners collaborate for GLPs, it should be noted that not all shipper-LSP collaborations necessarily follow this pattern, as partners may collaborate for reasons beyond the green factor. Although we attempted to capture this complexity by incorporating strategy-related control variables, we still recommended replicating the analysis on other types of partnerships to see whether GLPs thrive in them as well. Moreover, this study did not consider the impact of shipper industries on facilitating the GLPs, due to the imbalance in responses between the participating industries. Since this constrained us from treating shippers as different groups in the analysis, we call for rectifying this in future surveys. One other limitation is that the covered GLPs were represented by single variables (which enabled incorporating several GLPs). Further research may hence designate several variables to represent each GLP, which would reveal whether the two types of collaboration mechanisms have the same level of influence among them. Finally, as our survey covered actors in Sweden only, we recommend replicating our analysis in other countries.

\section{ORCID iDs}

Amer Jazairy Dhttp://orcid.org/0000-0003-0582-8942

Robin von Haartman (Dhttp://orcid.org/0000-0001-5541-7725

Maria Björklund Dhttp://orcid.org/0000-0003-0202-5917

\section{Note}

1. It is important to specify who is making relation-specific investments: LSPs, shippers or both. The contract logistics literature suggests that LSP-specific assets are the ones alleviating opportunism in logistics relationships (Cf. Huo et al., 2018; Large et al., 2011); thus, we shed light on these in particular. This choice is also in line with our definition of collaboration mechanisms as means to safeguard the relationship during its course.

\section{References}

Abbasi, M. and Nilsson, F. (2016), "Developing environmentally sustainable logistics: exploring themes and challenges from a logistics service providers' perspective", Transportation Research Part D: Transport and Environment, Vol. 46, pp. 273-283.

Acock, A.C. (2005), "Working with missing values", Journal of Marriage and Family, Vol. 67 No. 4, pp. 1012-1028.

Anderhofstadt, B. and Spinler, S. (2019), "Factors affecting the purchasing decision and operation of alternative fuel-powered heavy-duty trucks in Germany - a Delphi study", Transportation Research Part D: Transport and Environment, Vol. 73, pp. 87-107. 
Aronsson, H. and Huge-Brodin, M. (2006), "The environmental impact of changing logistics structures", International Journal of Logistics Management, Vol. 17 No. 3, pp. 394-415.

Awasthi, A., Adetiloye, T. and Crainic, T.G. (2016), "Collaboration partner selection for city logistics planning under municipal freight regulations", Applied Mathematical Modelling, Vol. 40 No. 1, pp. 510-525.

Bagozzi, R.P., Yi, Y. and Phillips, L.W. (1991), "Assessing construct validity in organizational research", Administrative Science Quarterly, Vol. 36 No. 3, pp. 421-458.

Bask, A., Rajahonka, M., Laari, S., Solakivi, T., Töyli, J. and Ojala, L. (2018), "Environmental sustainability in shipper-LSP relationships", Journal of Cleaner Production, Vol. 172, pp. 2986-2998.

Björklund, M. (2011), "Influence from the business environment on environmental purchasing: drivers and hinders of purchasing green transportation services", Journal of Purchasing and Supply Management, Vol. 17 No. 1, pp. 11-22.

Björklund, M. and Forslund, H. (2018), "A framework for classifying sustainable logistics innovations”, Logistics Research, Vol. 11 No. 1, pp. 1-12.

Björklund, M. and Johansson, H. (2018), "Urban consolidation centre - a literature review, categorisation, and a future research agenda", International Journal of Physical Distribution and Logistics Management, Vol. 48 No. 8, pp. 745-764.

Bollen, K.A. (1989), Structural Equations with Latent Variables, John Wiley \& Sons, New York, NY.

Bowersox, D.J. (1990), "Strategic benefits of logistics alliances", Harvard Business Review, Vol. 68, pp. 36-45.

Brekalo, L. and Albers, S. (2016), "Effective logistics alliance design and management", International Journal of Physical Distribution and Logistics Management, Vol. 46 No. 2, pp. 212-240.

Briggs, S.R. and Cheek, J.M. (1986), "The role of factor analysis in the development and evaluation of personality scales", Journal of Personality, Vol. 54 No. 1, pp. 106-148.

Brown, T.A. (2015), Confirmatory Factor Analysis for Applied Research, The Guilford Press, New York, NY.

Cao, M. and Zhang, Q. (2011), "Supply chain collaboration: impact on collaborative advantage and firm performance", Journal of Operations Management, Vol. 29 No. 3, pp. 163-180.

Centobelli, P., Cerchione, R. and Esposito, E. (2017), "Environmental sustainability in the service industry of transportation and logistics service providers: systematic literature review and research directions", Transportation Research Part D: Transport and Environment, Vol. 53, pp. 454-470.

Centobelli, P., Cerchione, R. and Esposito, E. (2020), "Pursuing supply chain sustainable development goals through the adoption of green practices and enabling technologies: a cross-country analysis of LSPs”, Technological Forecasting and Social Change, Vol. 153, 119920.

Choy, K.L., Li, C.L., So, S.C., Lau, H., Kwok, S.K. and Leung, D. (2007), "Managing uncertainty in logistics service supply chain", International Journal of Risk Assessment and Management, Vol. 7 No. 1, pp. 19-43.

Cleophas, C., Cottrill, C., Ehmke, J.F. and Tierney, K. (2019), "Collaborative urban transportation: recent advances in theory and practice", European Journal of Operational Research, Vol. 273 No. 3, pp. 801-816.

Coase, R.H. (1937), "The nature of the firm”, Economica, Vol. 4 No. 16, pp. 386-405.

Colicchia, C., Marchet, G., Melacini, M. and Perotti, S. (2013), "Building environmental sustainability: empirical evidence from logistics service providers", Journal of Cleaner Production, Vol. 59, pp. 197-209.

Cox, A. and Thompson, I. (1997), "Fit for purpose' contractual relations: determining a theoretical framework for construction projects", European Journal of Purchasing and Supply Management, Vol. 3 No. 3, pp. 127-135.
Collaboration mechanisms for green logistics 
IJPDLM 51,4

Danloup, N., Mirzabeiki, V., Allaoui, H., Goncalves, G., Julien, D. and Mena, C. (2015), "Reducing transportation greenhouse gas emissions with collaborative distribution: a case study", Management Research Review, Vol. 38 No. 10, pp. 1049-1067.

de Leeuw, S. and Fransoo, J. (2009), "Drivers of close supply chain collaboration: one size fits all?", International Journal of Operations and Production Management, Vol. 29 No. 7, pp. 720-739.

de Marco, A., Cagliano, A.C., Mangano, G. and Perfetti, F. (2014), "Factor influencing logistics service providers efficiency in urban distribution systems", Transportation Research Procedia, Vol. 3, pp. 499-507.

de Souza, R., Goh, M., Lau, H.C., Ng, W.S. and Tan, P.S. (2013), "Collaborative urban logistics synchronizing the last mile", Proceedings of the 8th International Conference on City Logistics, 17-19 June 2013.

Dyer, J.H. and Singh, H. (1998), "The relational view: cooperative strategy and sources of interorganizational competitive advantage”, Academy of Management Review, Vol. 23 No. 4, pp. 660-679.

Eng-Larsson, F. and Norrman, A. (2014), "Modal shift for greener logistics - exploring the role of the contract", International Journal of Physical Distribution and Logistics Management, Vol. 44 No. 10, pp. 721-743.

Erdoğan, S. and Miller-Hooks, E. (2012), “A green vehicle routing problem”, Transportation Research Part E: Logistics and Transportation Review, Vol. 48 No. 1, pp. 100-114.

Evangelista, P. (2014), "Environmental sustainability practices in the transport and logistics service industry: an exploratory case study investigation", Research in Transportation Business and Management, Vol. 12, pp. 63-72.

Evangelista, P., Colicchia, C. and Creazza, A. (2017), "Is environmental sustainability a strategic priority for logistics service providers?", Journal of Environmental Management, Vol. 198, pp. 353-362.

Evangelista, P., Santoro, L. and Thomas, A. (2018), "Environmental sustainability in third-party logistics service providers: a systematic literature review from 2000-2016", Sustainability, Vol. 10 No. 5, pp. 1-34.

Fors, C., Kircher, K. and Ahlström, C. (2015), "Interface design of eco-driving support systems-truck drivers' preferences and behavioural compliance", Transportation Research Part C: Emerging Technologies, Vol. 58, pp. 706-720.

Forza, C. (2002), "Survey research in operations management: a process-based perspective", International Journal of Operations and Production Management, Vol. 22 No. 2, pp. 152-194.

George, D. and Mallery, P. (2010), SPSS for Windows Step by Step: A Simple Guide and Reference, 17.0, update, 10th ed., Pearson Education, Boston.

Ghosh, A. and Fedorowicz, J. (2008), "The role of trust in supply chain governance", Business Process Management Journal, Vol. 14 No. 4, pp. 453-470.

Goes, G., Bandeira, R., Gonçalves, D., D’Agosto, M.D.A. and Oliveira, C. (2020), "The effect of ecodriving initiatives toward sustainable urban waste collection", International Journal of Sustainable Transportation, Vol. 14 No. 8, pp. 569-578.

Goh, S.H. (2020), "Barriers to low-carbon warehousing and the link to carbon abatement", International Journal of Physical Distribution and Logistics Management, Vol. 49 No. 6, pp. 679-704.

Grant, D.B., Trautrims, A. and Wong, C.Y. (2017), Sustainable Logistics and Supply Chain Management: Principles and Practices for Sustainable Operations and Management, Kogan Page Publishers, London.

Guerrero-Ibanez, J.A., Zeadally, S. and Contreras-Castillo, J. (2015), "Integration challenges of intelligent transportation systems with connected vehicle, cloud computing, and internet of things technologies”, IEEE Wireless Communications, Vol. 22 No. 6, pp. 122-128. 
Guler, S.I., Menendez, M. and Meier, L. (2014), "Using connected vehicle technology to improve the efficiency of intersections", Transportation Research Part C: Emerging Technologies, Vol. 46, pp. 121-131.

Hair, J., Black, W.C., Babin, B.J., Anderson, R.E. and Tatham, R.L. (2010), Multivariate Data Analysis A Global Perspective, Global ed., Pearson, Edinburgh.

Halldórsson, Á. and Skjøtt-Larsen, T. (2004), "Developing logistics competencies through third party logistics relationships", International Journal of Operations and Production Management, Vol. 24 No. 2, pp. 192-206.

Hofmann, E., Solakivi, T., Töyli, J. and Zinn, M. (2018), "Oil price shocks and the financial performance patterns of logistics service providers”, Energy Economics, Vol. 72, pp. 290-306.

Huang, Y., Ng, E.C., Zhou, J.L., Surawski, N.C., Chan, E.F. and Hong, G. (2018), "Eco-driving technology for sustainable road transport: a review", Renewable and Sustainable Energy Reviews, Vol. 93, pp. 596-609.

Huge-Brodin, M., Sweeney, E. and Evangelista, P. (2020), "Environmental alignment between logistics service providers and shippers - a supply chain perspective", International Journal of Logistics Management, Vol. 31 No. 3, pp. 575-605.

Huo, B., Liu, C., Chen, H. and Zhao, X. (2017), "Dependence, trust, and 3PL integration: an empirical study in China", International Journal of Physical Distribution and Logistics Management, Vol. 47 No. 9, pp. 927-948.

Huo, B., Ye, Y., Zhao, X., Wei, J. and Hua, Z. (2018), "Environmental uncertainty, specific assets, and opportunism in 3PL relationships: a transaction cost economics perspective", International Journal of Production Economics, Vol. 203, pp. 154-163.

Jazairy, A. (2020), "Aligning the purchase of green logistics practices between shippers and logistics service providers", Transportation Research Part D: Transport and Environment, Vol. 82, p. 102305.

Jazairy, A. and von Haartman, R. (2020), "Analysing the institutional pressures on shippers and logistics service providers to implement green supply chain management practices", International Journal of Logistics Research and Applications, Vol. 23 No. 1, pp. 44-84.

Jazairy, A. and von Haartman, R. (2021), "Measuring the gaps between shippers and logistics service providers on green logistics throughout the logistics purchasing process", International Journal of Physical Distribution and Logistics Management, Vol. 51 No. 1, pp. 25-47.

Jazairy, A., Lenhardt, J. and von Haartman, R. (2017), "Improving logistics performance in crossborder 3PL relationships", International Journal of Logistics Research and Applications, Vol. 20 No. 5, pp. 491-513.

Kavakeb, S., Nguyen, T.T., McGinley, K., Yang, Z., Jenkinson, I. and Murray, R. (2015), "Green vehicle technology to enhance the performance of a European port: a simulation model with a costbenefit approach", Transportation Research Part C: Emerging Technologies, Vol. 60, pp. 169-188.

Khaslavskaya, A. and Roso, V. (2019), "Outcome-driven supply chain perspective on dry ports", Sustainability, Vol. 11 No. 5, p. 1492.

Lai, F., Li, D., Wang, Q. and Zhao, X. (2008), "The information technology capability of third-party logistics providers: a resource-based view and empirical evidence from China", Journal of Supply Chain Management, Vol. 44 No. 3, pp. 22-38.

Large, R.O., Kramer, N. and Hartmann, R.K. (2011), "Customer-specific adaptation by providers and their perception of 3pl-relationship success", International Journal of Physical Distribution and Logistics Management, Vol. 41 No. 9, pp. 822-838.

Large, R.O., Kramer, N. and Hartmann, R.K. (2013), "Procurement of logistics services and sustainable development in Europe: fields of activity and empirical results", Journal of Purchasing and Supply Management, Vol. 19 No. 3, pp. 122-133.
Collaboration mechanisms for green logistics 
IJPDLM 51,4

Lieb, K.J. and Lieb, R.C. (2010), "Environmental sustainability in the third-party logistics (3PL) industry", International Journal of Physical Distribution and Logistics Management, Vol. 40 No. 7, pp. 524-533.

Lun, Y.V., Lai, K.H., Wong, C.W. and Cheng, T.C.E. (2015), "Greening propensity and performance implications for logistics service providers", Transportation Research Part E: Logistics and Transportation Review, Vol. 74, pp. 50-62.

Martinsen, U. and Björklund, M. (2012), "Matches and gaps in the green logistics market", International Journal of Physical Distribution and Logistics Management, Vol. 42 No. 6, pp. 562-583.

Martinsen, U. and Huge-Brodin, M. (2014), "Environmental practices as offerings and requirements on the logistics market”, Logistics Research, Vol. 7 No. 1, p. 115.

Molina-Besch, K. and Pålsson, H. (2014), "Packaging for eco-efficient supply chains: why logistics should get involved in the packaging development process", Sustainable Logistics, Emerald Group Publishing, Bingley, West Yorkshire, pp. 137-163.

Monios, J. and Bergqvist, R. (2016), "Drivers for vertical integration in the rail sector - using wagons as 'relationship specific assets", International Journal of Logistics Management, Vol. 27 No. 2, pp. 533-551.

Neto, J.Q.F., Bloemhof-Ruwaard, J.M., van Nunen, J.A. and van Heck, E. (2008), "Designing and evaluating sustainable logistics networks", International Journal of Production Economics, Vol. 111 No. 2, pp. 195-208.

Nilsson, F.R., Sternberg, H. and Klaas-Wissing, T. (2017), "Who controls transport emissions and who cares? Investigating the monitoring of environmental sustainability from a logistics service provider's perspective", International Journal of Logistics Management, Vol. 28 No. 3, pp. 798-820.

Piecyk, M.I. and Björklund, M. (2015), "Logistics service providers and corporate social responsibility: sustainability reporting in the logistics industry", International Journal of Physical Distribution and Logistics Management, Vol. 45 No. 5, pp. 459-485.

Poppo, L., Zhou, K.Z. and Zenger, T.R. (2008), "Examining the conditional limits of relational governance: specialized assets, performance ambiguity, and long-standing ties”, Journal of Management Studies, Vol. 45 No. 7, pp. 1195-1216.

Rajahonka, M., Bask, A., Yawar, S.A. and Tinnilä, M. (2019), "The physical internet as enabler of new business models enhancing greener transports and the circular economy", Sustainable and Efficient Transport, Edward Elgar Publishing.

Rogerson, S. and Santén, V. (2017), "Shippers' opportunities to increase load factor: managing imbalances between required and available capacity", International Journal of Logistics Research and Applications, Vol. 20 No. 6, pp. 581-603.

Sallnäs, U. (2016), "Coordination to manage dependencies between logistics service providers and shippers: an environmental perspective", International Journal of Physical Distribution and Logistics Management, Vol. 46 No. 3, pp. 316-340.

Sallnäs, U. and Huge-Brodin, M. (2018), "De-greening of logistics? Why environmental practices flourish and fade in provider-shipper relationships and networks", Industrial Marketing Management, Vol. 74, pp. 276-287.

Sanchez-Rodrigues, V., Potter, A. and Naim, M.M. (2010), "The impact of logistics uncertainty on sustainable transport operations", International Journal of Physical Distribution and Logistics Management, Vol. 40 Nos 1/2, pp. 61-83.

Selviaridis, K. and Spring, M. (2007), "Third party logistics: a literature review and research agenda", International Journal of Logistics Management, Vol. 18 No. 1, pp. 125-150.

Sinkovics, R.R., Kuivalainen, O. and Roath, A.S. (2018), "Value co-creation in an outsourcing arrangement between manufacturers and third party logistics providers: resource commitment, innovation and collaboration”, Journal of Business and Industrial Marketing, Vol. 33 No. 4, pp. 563-573. 
Skjøtt-Larsen, T. (2000), "Third party logistics - from an interorganizational point of view", International Journal of Physical Distribution and Logistics Management, Vol. 30 No. 2, pp. 112-127.

Sureeyatanapas, P., Poophiukhok, P. and Pathumnakul, S. (2018), "Green initiatives for logistics service providers: an investigation of antecedent factors and the contributions to corporate goals", Journal of Cleaner Production, Vol. 191, pp. 1-14.

Tabachnick, B.G. and Fidell, L.S. (2007), Using Multivariate Statistics, 5th ed., Allyn and Bacon, Boston.

Triantafyllou, M.K., Cherrett, T.J. and Browne, M. (2014), "Urban freight consolidation centers: case study in the UK retail sector", Transportation Research Record, Vol. 2411 No. 1, pp. 34-44.

Verghese, K. and Lewis, H. (2007), "Environmental innovation in industrial packaging: a supply chain approach", International Journal of Production Research, Vol. 45 Nos 18-19, pp. 4381-4401.

Wahab, S.N., Sayuti, N.M. and Talib, M.S.A. (2018), “Antecedents of green warehousing: a theoretical framework and future direction", International Journal of Supply Chain Management, Vol. 7 No. 6, pp. 382-388.

White, G.R., Wang, X. and Li, D. (2015), "Inter-organisational green packaging design: a case study of influencing factors and constraints in the automotive supply chain", International Journal of Production Research, Vol. 53 No. 21, pp. 6551-6566.

Williamson, O.E. (1979), "Transaction-cost economics: the governance of contractual relations", The Journal of Law and Economics, Vol. 22 No. 2, pp. 233-261.

Williamson, O.E. (1981), "The economics of organization: the transaction cost approach", American Journal of Sociology, Vol. 87 No. 3, pp. 548-577.

Wolf, C. and Seuring, S. (2010), "Environmental impacts as buying criteria for third party logistical services", International Journal of Physical Distribution and Logistics Management, Vol. 40 Nos 1/2, pp. 84-10.

Yuan, Y., Feng, B., Lai, F. and Collins, B.J. (2018), "The role of trust, commitment, and learning orientation on logistic service effectiveness", Journal of Business Research, Vol. 93, pp. 37-50.

Zacharia, Z.G., Sanders, N.R. and Nix, N.W. (2011), "The emerging role of the third-party logistics provider (3PL) as an orchestrator", Journal of Business Logistics, Vol. 32 No. 1, pp. 40-54.

Zavalko, A. (2018), "Applying energy approach in the evaluation of eco-driving skill and eco-driving training of truck drivers", Transportation Research Part D: Transport and Environment, Vol. 62, pp. 672-684.

\section{Corresponding author}

Amer Jazairy can be contacted at: amrjai@hig.se
Collaboration mechanisms for green logistics 


\section{IJPDLM \\ Appendix}

\section{Survey instrument}

Version 1 (shippers)

1. Think of an environmentally conscious logistics services provider (LSP) who is hired by your company.

2. Why did you choose to work with that LSP? Estimate the importance of the following factors for this LSP's selection (1: low importance, 5 : high importance):

Service quality (e.g. accuracy in order fulfilment)

Environmental sustainability performance (e.g. reducing $\mathrm{CO}_{2}$ emissions)

Innovation capability

3. Describe your company's relationship with this environmentally conscious LSP:

\begin{tabular}{|c|c|c|}
\hline $\begin{array}{l}\text { The LSP offers you the same services that they offer to } \\
\text { every other buyer }\end{array}$ & $(\mathrm{c})(\mathrm{)})(\mathrm{)})(\mathrm{)})$ & $\begin{array}{l}\text { The LSP offers you special services that are unique for your } \\
\text { requirements }\end{array}$ \\
\hline You agreed on a short-term contract (e.g. less than 1 year) & () & You agreed on a long-term contract (e.g. $>=5$ years) \\
\hline $\begin{array}{l}\text { The LSP did not invest in special equipment and assets } \\
\text { (tangible or non-tangible) for you in particular }\end{array}$ & ()()()()() & $\begin{array}{l}\text { The LSP invested in special equipment and assets (tangible } \\
\text { or non-tangible) for you in particular }\end{array}$ \\
\hline You do not exchange knowledge nor learn from each other & ( ) & You heavily exchange knowledge and learn from each other \\
\hline ween each other & ()()()()() & You do exchange personnel between each other \\
\hline Your IT systems are not integrated & ()()()() & Your IT systems are highly integrated \\
\hline
\end{tabular}

4. To what extent does your company implement the following green logistics practices in collaboration with this environmentally conscious LSP (1: very low; 5 : very high)?

- Choice of transport mode for the environment (e.g. choosing rail instead of trucks, intermodal platforms)

- Transport management for the environment (e.g. increase fill rate, route optimization)

- Logistics system design for the environment (e.g. reduced transport through better choice of distribution centres, urban consolidation centres)

Vehicle technologies (e.g. more efficient engines, less polluting vehicles, less air resistance)

Eco-driving (e.g. skills for efficient driving, supportive in-vehicle devices)

Alternative fuels (e.g. biofuels, electric trucks)

Green and efficient warehouses (through e.g. energy saving, renewable energies)

Green packaging (e.g. package design, use, reuse, recycling)

Version 2 (LSPS)

1. Think of an environmentally conscious logistics buyer who is hiring your company.

2. Why did this buyer choose to work with your company? Estimate the importance of the following factors for choosing your company (1: low importance, 5 : high importance):

- Service quality (e.g. accuracy in order fulfilment)

Environmental sustainability performance (e.g. reducing $\mathrm{CO}_{2}$ emissions)

Innovation capability

3. Describe your company's relationship with this environmentally conscious logistics buyer:

\begin{tabular}{|c|c|c|}
\hline $\begin{array}{l}\text { You offer this buyer the same services that you offer to } \\
\text { every other buyer }\end{array}$ & $(\mathrm{)})(\mathrm{)})(\mathrm{)})(\mathrm{)}$ & $\begin{array}{l}\text { You offer special and unique services to match this buyer's } \\
\text { requirements }\end{array}$ \\
\hline You agreed on a short-term contract (e.g. less than 1 year) & $(\mathrm{)}(\mathrm{)})(\mathrm{)})(\mathrm{)})$ & You agreed on a long-term contract (e.g. $>=5$ years) \\
\hline $\begin{array}{l}\text { You did not invest in special equipment and assets (tangible } \\
\text { or non-tangible) for this particular buyer }\end{array}$ & ()()()()() & $\begin{array}{l}\text { You invested in special equipment and assets (tangible or } \\
\text { non-tangible) for this particular buyer }\end{array}$ \\
\hline You do not exchange knowledge nor learn from each other & ()()()()() & You heavily exchange knowledge and learn from each other \\
\hline You do not exchange personnel between each other & $(\mathrm{)}(\mathrm{)})(\mathrm{)})(\mathrm{)})$ & You do exchange personnel between each other \\
\hline Your IT systems are not integrated & $($ )( )( )( )( ) & Your IT systems are highly integrated \\
\hline
\end{tabular}

4. To what extent does your company implement the following green logistics practices in collaboration with this environmentally conscious logistics buyer (1: very low; 5 : very high)?

- Choice of transport mode for the environment (e.g. choosing rail instead of trucks, intermodal platforms)

- Transport management for the environment (e.g. increase fill rate, route optimization)

Logistics system design for the environment (e.g. reduced transport through better choice of distribution centres, urban consolidation centres)

Vehicle technologies (e.g. more efficient engines, less polluting vehicles, less air resistance)

Eco-driving (e.g. skills for efficient driving, supportive in-vehicle devices)

Alternative fuels (e.g. biofuels, electric trucks)

Green and efficient warehouses (through e.g. energy saving, renewable energies)

Green packaging (e.g. package design, use, reuse, recycling) 


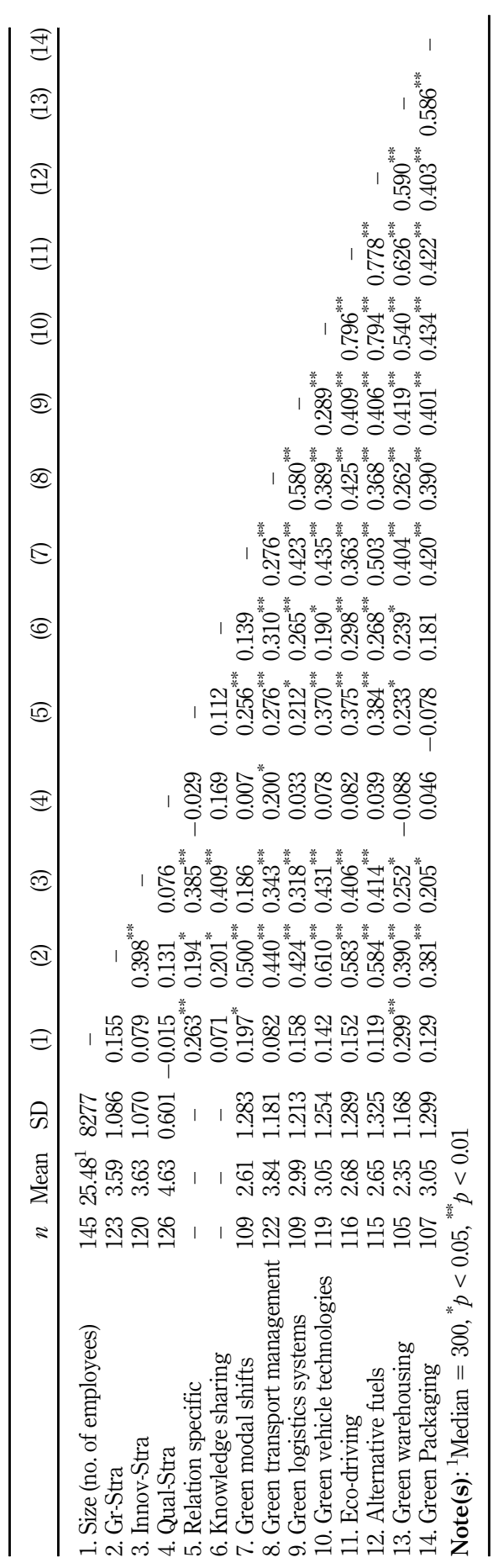

Collaboration mechanisms for green logistics 
IJPDLM

51,4

448

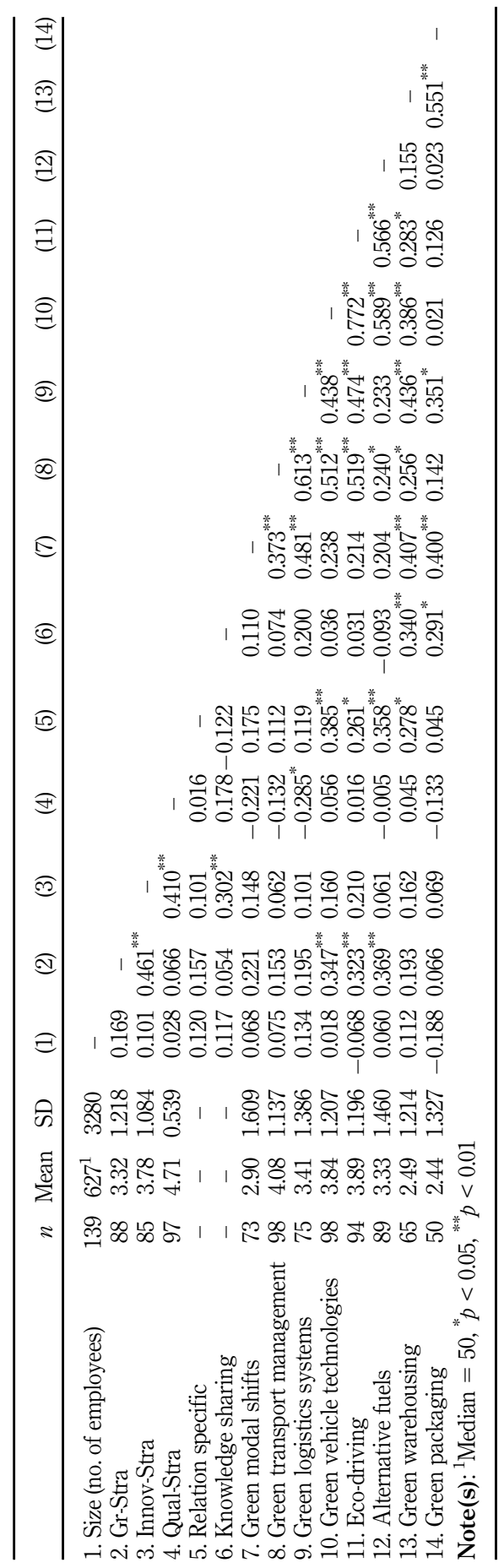

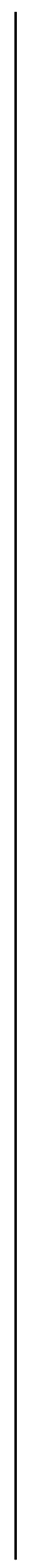

Table A2.

Descriptive statistics and correlations (LSPs) 